\title{
Influence of Non-traditional Teaching Techniques on the Learning Process of University Students
}

\author{
Mercedes Regadío García \\ Autónoma University of Madrid, Spain
}

\begin{abstract}
Changes in the way the lectures are done in college are expected to become more and more frequent and important over the next few years. This follows from the priorities defined in the framework of the EHEA (European Higher Education Area) and in the assessment of the teaching capacity of professors. This work compares two didactical methods and the influence of integrating information and communication technologies (ICT) into the subject of Geology, for the first-year group of Biology during the 2009/10 academic course. In total, 70 students participated, half of them received four lessons following one methodology (cooperative learning, CL) and the other half took again four lessons but based on other methodology (case method, CM). In general, both techniques complied fairly well with the predefined goals of the curriculum and with the exams and surveys outcomes when comparing to the previous 2008/09 course. In addition, a blog was introduced in the second half of the academic year to the whole group. The paper proves that CM is more effective than CL and that the blog has been very well received by the students. This study provides details on what steps the professor takes to carry out these procedures, the pros and cons of each and the reasons why the use of one or another approach is more convenient, with regard to objective evaluations.
\end{abstract}

\section{Introduction}

The last decades saw the escalation of two major innovative trends within universities in most of the countries: the implementation of the European Higher Education Area (EHEA) and the evaluation of teaching capacity of professors.

The antecedent of the EHEA is the Bologna Process: a voluntary procedure developed by the European Union (EU) which consists of carrying out a series of actions in order to achieve the educational convergence. This Bologna process started when 29 Ministers of Education signed it in 1999 and their countries had to begin educational reforms to carry out reference framework, i.e. the EHEA [1]. One decade after, during the Budapest-Vienna Ministerial Conference (2010), the EHEA became true and today it consists of 48 countries; including United
Kingdom, Germany, Belgium, Switzerland, Azerbaijan, Armenia, Russian Federation or Holy See [2].

Moving towards an educational convergence involves some reforms:

- To implement comparable and equivalent curricula (to be able to validate the high degrees obtained in the different countries).

- To adapt the curricula to the social demands (in order to satisfy the needs of the labour market).

In the first case (qualifications recognition and coherence between universities), the objective is to eradicate the segmentation of the higher education European policy and to encourage free circulation, establishment and exchange of graduates between the countries. In the second case, the aim is to eliminate the trend that just-graduated students do not find a job or, if they do, it does not fit their background education.

Thus, the many countries which participate in this process must assure that professors reorganize their didactic methods to accomplish these goals (promoting an academically active student and modifying the quality criteria of curricula to minimize the present unemployment). Now, the effort aimed at getting universities to meet the needs of the people: the concept of social dimension of higher education was introduced.

In addition to educational policies, another change in the university system is the evaluation of teaching capacity of professors [3].

On the whole, professors have four main obligations: research, management, transmission of knowledge and teaching. This is not an easy task and there is a conflict about how to distribute the limited time among these multiple duties.

Professors have traditionally dedicated more time and interest to research than to teaching [4], as rewards for teaching quality were lower than on researching. Nevertheless, this has changed in the last years because governments want to ensure high standards of education and universities need to strengthen their competitiveness to attract more potential students. In agreement with this, universities now offer pedagogy training courses for their professors (e.g., [5]) and professors are supervised, evaluated and get feedback on their teaching performance by government institutions [6]. 
Therefore, when professors are doing well, they are rewarded with a higher income or/and a promotion. Objectively verifiable and predefined indicators, readily available on the Internet, easily quantifiable and increasingly specific; are used to assess the effectiveness of professors' performance. In more and more countries, institutions are created to guarantee the spread of good practices and keep the education system under review. The Academic Audit Unit (1989) was the first in monitoring academic standards in United Kingdom universities. Since 1997, its functions were transferred in to the Quality Assurance Agency for Higher Education. In Spain, ANECA is the state foundation that aims to improve the quality of higher education system through the evaluation, certification and accreditation of university teachers and institutions.

In response to that, teaching methods have changed in the last two decades. Nevertheless, it is not only important to change, but also to guarantee the improvement of the new implemented practices. The main objective of this paper is to compare two teaching methodologies together with a computer application and their adjustment to accomplish the new educational challenges.

\section{Methodology}

This section covers an overview of the objectives, the field of study according to the proposed objectives, the sample description (i.e., the university students), the selection criteria of the didactical methods that were applied, the adaptation of some parts of the curriculum to the methods concerned, the procedures for conducting the class, the main conditions under which students will operate, the evaluation criteria which will be applied to the students and the survey and evaluation of the investigation as a whole.

\subsection{Objectives and sample}

During the 2009/10 academic year, a pioneering experience was carried out in one group of the $1^{\text {st }}$ year of Bachelor of Science in Biology for the subject of Geology. The aim was to improve the learning process of the undergraduates by the development of skills, through the active implication of the student and the acquisition and application of the knowledge.

Skills are considered here to be on the one hand capacities such as teamwork, search of information from different sources, subtraction of the important ideas, oral expression, discussion, problem solving, reading comprehension, critical and reflective inquiry, information management or evaluation of alternatives. On the other hand, they also refer to the gradual replacement of the reproductive learning by the constructive learning; i.e., that the subject does contribute with something to the student. The reproductive learning is based on a mere repetition, of everything that has been said, by heart; meanwhile the constructive learning is based on recalling the main idea, because the speech was previously fully understood (it is not a repetition of words spoken). This difference makes the constructive learning produce lasting outcomings [7].

First of all, the previous 2008/09 course, of $1^{\text {st }}$ of Bachelor of Science in Biology, was analysed to identify problems and to use them as a starting point for the correction of the present work. After this study on the status of literacy and learning process, the problems found were:

- Low motivation, expectations and goals of the undergraduates (increasing their motivation and improving their vision of the subject).

- Little student-professor interaction due to the class dynamic (increasing the involvement of the students, promoting discussions about a subject on which people have different views, improving the environment inside the classroom).

- Difficulties in the ability of reasoning and solving problems [8] (helping the students to use their thought to solve problems, not giving directly the solution but teaching them how to find it).

- Limited development of skills (practicing them with specific exercises).

- Need of fostering the reading and writing of academic texts, fundamental tools for understanding and communicating the knowledge [9] (training those capacities to facilitate the comprehension of texts, books, articles).

Although these factors were separately enumerated, they cannot be considered as isolated because they are ultimately connected with each other, being motivation the main point in all of them.

According to the previously identified problems, two teaching techniques and a computer application were chosen to verify if they can help to solve them: the cooperative learning, CL, the case method, CM and a blog.

Following [10], motivation is positively related to the autonomy, the sense of belonging and the need of skill. In the CL, students work in a very autonomous way and sense of belonging is developed between them as their scores depend on the scores of the other components of the same teamwork (section 2.2).

In the CM, students must prepare a little essay (on their own and out of class) and students' participation increases during the pooling, which also contributes to increase their motivation and learning. In both methodologies, students work in subgroups which helps to acquire some of the skills specified before and the material used (texts, figures, tables and sketches) forces students to make an effort on 
comprehension and on synthesis (to get the main ideas and concepts and transmit them to other people). Therefore, promoting classes that use techniques such as CL and CM can provide a favourable climate for motivation, involvement, acquisition of skills, problem solving and reading and writing practise.

It is also aimed, within the framework of the objectives, to analyse what effect the information and communication technology (ICT) has, specifically to this end, a blog was introduced in the second half of the academic year. Different variables were tested in order to find out if the blog is a mechanism to facilitate the students' learning process and in order to identify the reasons.

\subsection{CL and CM process}

The 70 first year-biologist-undergraduates from the Autónoma University of Madrid, were divided in two groups of 35 students during eight classes (Geology seminars) to compare the two pedagogical approaches: CL was applied in group 1 during four classes of 50 minutes-lasting and CM was applied in group 2 for four other classes of the same duration. Thus, four lessons were prepared by duplicate, one replicate following the CL standards (group 1) and the other was adjusted to the CM principles (group 2 ). In both groups, the students worked in subgroups of five for the four sessions (Figure 1). This size of subgroup was chosen because bigger subgroups make it more difficult that everybody takes part in the activity in a similar proportion and smaller subgroups have a dynamic of much smaller participation.

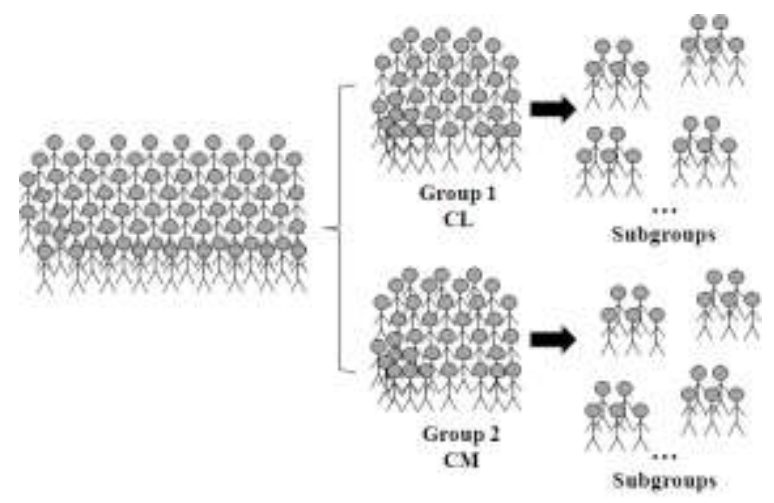

Figure 1. Structure of groups and subgroups

On the one hand, in the CL process the professor provides a text with all the necessary information to the undergraduates. The document is divided into five parts; each one is assigned to one member of the five-student subgroups. For the first five minutes, they must read in silence and on their own their corresponding part (student 1 will read part 1, student 2 will read part 2, and so on, Figure 2.a).

Then, new subgroups are formed: all the students that have read the same part, from the different teams, are clustered together. In the following 15 minutes, they must comment what they have read, discuss the doubts that could exist and check if they agree in the interpretation of the main points (Figure 2.b). Next, they go back to their original subgroups and each one explains to the rest of the group his/her part in 25 minutes (Figure 2.c). It is in that moment when the overall information is known by all the members of the team, i.e., by all the students. Finally, they must complete an individual test without using any material. The professor hands back the corrected tests to the students the following week. The evaluation takes into account the individual scores and the average score of the five members of the subgroup. The individual score is based $50 \%$ on the assistance and $50 \%$ on the test. The professor does not explain the topic, but clarifies students' doubts. The students obtain the key issues on their own and with the help of other classmates.

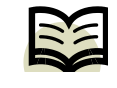

(a)

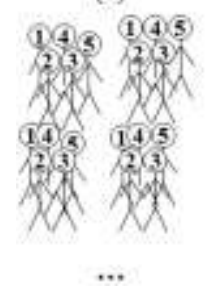

Figure 2. CL organization (a) Personal reading of the corresponding part (b) Discussion in subgroups that have read the same part (c) Pooling in the original subgroups

On the other hand, in the CM process the professor explains the main concepts and ideas of the topic during the first 15-20 minutes. Then, a case with questions is given to each student. The case consists of a short narrative, graphics, tables, sketches and/or any other resource that mediates in the reasoning process. The subgroups read, analyse the case and take reflective thinking answers for the questions. Although each subgroup has to reach an agreement for the answers, every student has to answer the questionnaire and hand it back 10 minutes before the session ends. The last 10 minutes are dedicated to the pooling of the consensus solutions in each subgroup, what promotes possible discussions between subgroups. Finally, the students are asked to do an essay about a specific topic at home, that they will have to hand the next week. The evaluation consists of $50 \%$ the assistance, $40 \%$ the questionnaire and $10 \%$ the outer class activity. 
It is important the students know and understand what they supposed to be doing during the four seminars in both CL and CM. Hence, at the beginning of each one, the professor gave detailed oral instructions and examples, emphasizing the procedures, concepts and evaluation of the activity.

\subsection{Blog tool}

Throughout the academic year, the students took ten two-hour practical classes. At first, no ICT was provided, but after the practice exam of the first semester a blog was created (http://geologiauam. blogspot.com) with the following material available for the students:

- Compulsory and optional exercises.

- Solutions to the exercises.

- Non-university announcements related to the subject.

- Tutorials notifications.

- Class material.

- Qualification list.

- Announcements of exams and review exams dates.

- Activities guide, e.g., information on field trips, including different trails of geological and environmental interest, photographs, explanations, map references as well as detailed instructions on how to get there by public and private transport.

- Anonymous survey on professor evaluation completed by the students.

To see the effect of the introduction of the blog, the following parameters were compared in the first semester (no blog) and the second semester (with blog): individual grades, exam pass rate, average grade of the whole group, percentage of students with a grade equal to or higher than 3.5 (on a 0-5 scale) and evaluation of the blog by the students in the anonymous survey.

This survey (Appendix A) collected the opinion of the students about the professor's attitude and performance in a wide range of aspects and during all kind of interventions. The students were required to complete it in the blog, at the end of the course. Together, with the grades and the assistance, are considered as evaluation criteria of the learning results.

\section{Results}

Thanks to repeating the topics of seminars for each group with each methodology, we can compare the results between both (CL and CM) and analyse what can cause their differences. For that, we will use the assistance and the evaluations (short- and long-term learning assessment).
Regarding the assistance, between $80-97 \%$ of the students attended the four seminars, which was considered to be a good sign. Nevertheless, the number of attendances was lower in group 1 (CL) than in group $2(\mathrm{CM})$ : the absences rose over time for the CL group (from 1-2 to 6-7) and remain constant along all the seminars for the $\mathrm{CM}$ group (around 2-3) (Figure 3).

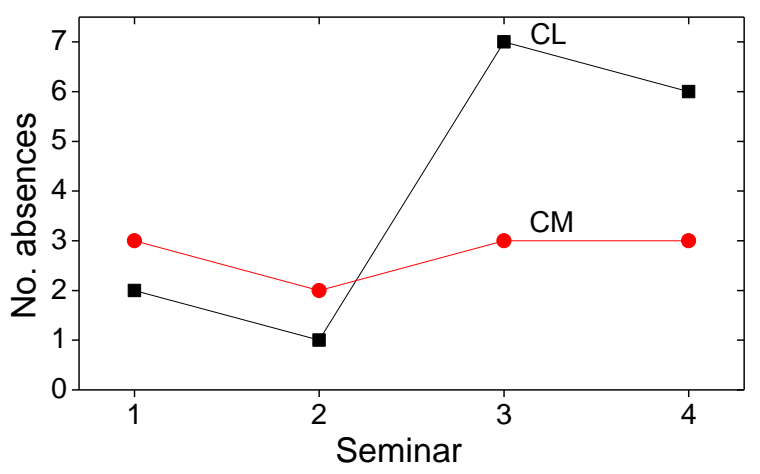
Figure 3. Bivariate plot of attendance-
versus-seminars

To clearly show the results of the students's scores (Appendix B), average data of scores and attendance of undergraduates according to the methodology (CL and CM) and to the seminar (I, II, III and IV) are summarized in Table 1 (short-term examinations) and Table 2 (long-term examination). Taking into account the evaluations of the exercises handed out in each seminar (Table 1), the CM shows the best results.

Table 1. Learning assessment: short-term

\begin{tabular}{|c|c|c|c|c|c|c|c|}
\hline & \multicolumn{5}{|c|}{$\underline{\text { Seminar I Seminar II Seminar III }}$} & \multicolumn{2}{|c|}{$\underline{\text { Seminar IV }}$} \\
\hline & CL $\mathrm{CM}$ & $\mathrm{CL}$ & $\mathrm{CM}$ & CL & $\mathrm{CM}$ & $\mathrm{CL}$ & $\mathrm{CM}$ \\
\hline Assistances & 33 & 34 & 33 & 28 & 32 & 29 & 32 \\
\hline Absences & 3 & 1 & 2 & 7 & 3 & 6 & 3 \\
\hline Average score ${ }^{a}$ & 7.908 .11 & 7.36 & 7.91 & 8.29 & 8.89 & 6.77 & 7.17 \\
\hline
\end{tabular}

As it is not only the quantity, but also the timeretention capacity (which is directly related to the comprehension) an indicator of the learning quality; another test about the seminars was done sometime after. This final test was not announced to the students. Table 2 shows average scores and attendance of this test (all the grades are in Table B.3, Appendix B).

Table 2. Learning assessment: long-term

\begin{tabular}{lcc}
\hline & CL & CM \\
\hline Assistances & 29 & 32 \\
Absences & 6 & 3 \\
Seminar I & 2.02 & 2.06 \\
Seminar II $^{\mathrm{b}}$ & 1.10 & 1.59 \\
Seminar III $^{\mathrm{b}}$ & 1.24 & 1.53 \\
\hline \multicolumn{2}{c}{${ }^{\mathrm{b}}$ Average scores $(0-3)$}
\end{tabular}


The reason for not including seminar IV there, was because the test was done the same day as this seminar, so it would not assess the long-term learning aspect. Table 3 illustrates the chronology of the sessions.

\section{Table 3. Chronology chart (mm/dd/yy)}

\begin{tabular}{ccccc}
\cline { 2 - 5 } & Seminar I & Seminar II & Seminar III & $\begin{array}{c}\text { Seminar IV } \\
\text { Final test }\end{array}$ \\
\hline CL & $10 / 22 / 2009$ & $12 / 03 / 2009$ & $02 / 19 / 2010$ & $04 / 08 / 2010$ \\
CM & $10 / 01 / 2009$ & $11 / 12 / 2009$ & $01 / 28 / 2010$ & $03 / 11 / 2010$ \\
\hline
\end{tabular}

Not only by the marks (indicator of the quantity and duration of the learning), but also by the attendance (indicator of the student's interest on the subject) the best results were obtained with the CM in all cases (Tables 1 and 2).

Furthermore, the overall effect of the experience was assessed comparing the whole handled group $(2009 / 10)$ with the control group of the previous year (2008/09). Mean scores and surveys were used for this purpose. In 2008/09, 54\% of the students passed the normal practical exam and $11 \%$ of them did not attend it; while in $2009 / 10,70 \%$ of the students passed and the non-attendance percentage was $4 \%$. A survey answered by the students about their satisfaction on their professor's job was also used. The questions are grouped into four categories: questions about the motivational feature of the professor, questions about the guidance job done by the professor, questions about the accomplishment of the rules by the professor and a general opinion of the professor's job. In the first and last group of questions, the marks were higher in 2009/10 (5.23 and 5.6) than in 2008/09 (4.88 and 4.67) (the punctuation goes from 1 to 7 ).

Regarding the blog results, most of the cases the students increased the grade since the blog came into use in the second semester (Figure 4 and 5).

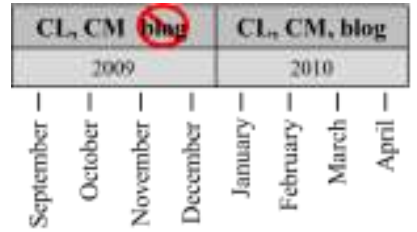

Figure 4. Time line of the different applied techniques

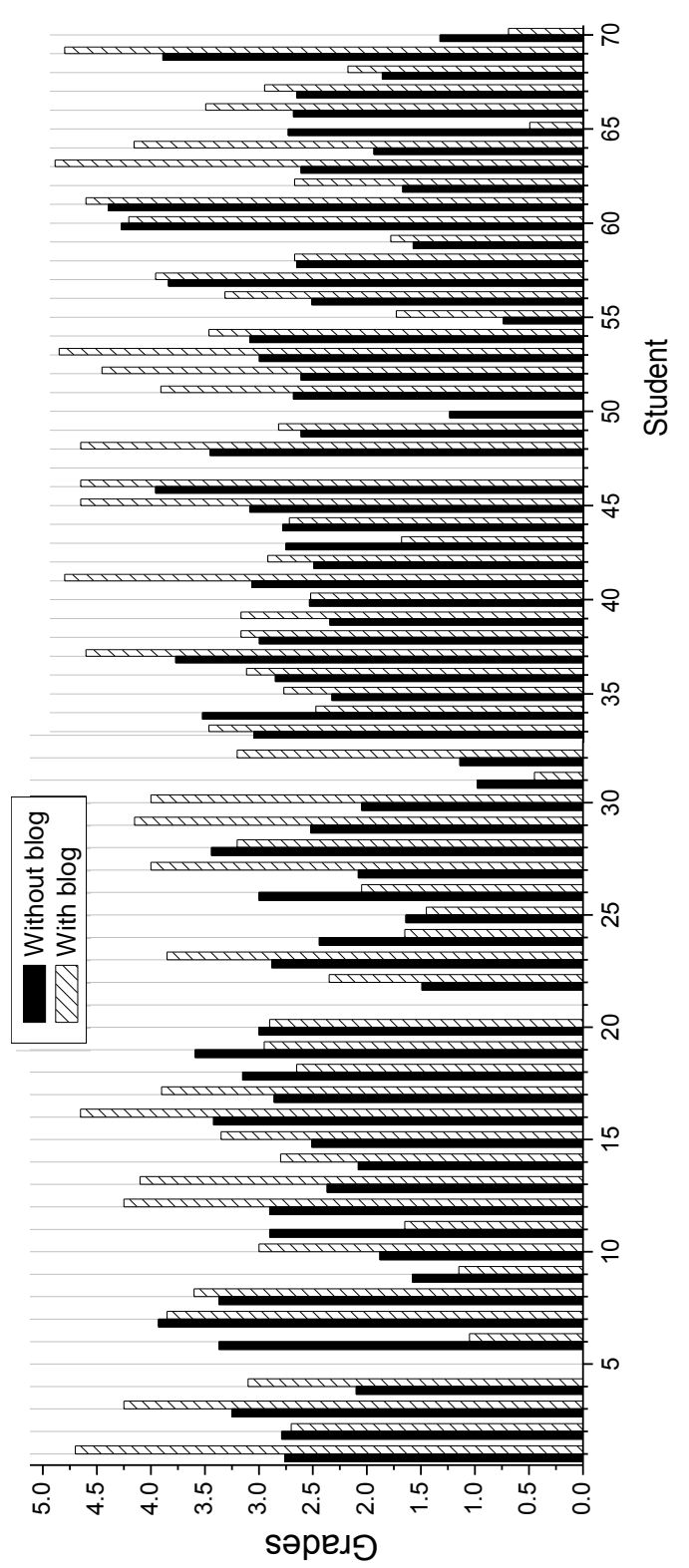

Figure 5. Students grades (on a 0-5 scale) in the first semester evaluation (without blog) and in the second semester evaluation (with blog)

\section{Discussion}

\subsection{CL, CM and blog}

Considering the methodology (section 2.2), it would be expected that the attendance in CL was higher than in CM, because of the bigger engagement between the classmates of the same subgroup, as their individual scores depend on the evaluation of the other members of the subgroup and as a problematic functioning of the subgroup comes up when a member is missed (Figure 2). However, it 
was the other way around and less assistance in the CL group was observed.

The trend to a minor assistance in the last seminars and the lower scores obtained with CL make CM more successful. This may be explained by the main difference between both methods that the participation of the professor is greater in CM as he/she explains the main concepts in the beginning of the lecture, what facilitates the task that the students will accomplish next. As the students are attending the first year of university, the level of assistance given to them must be more significant than in the case of undergraduates in higher courses. Moreover, autonomy in class normally promotes rejection, complaints and resignation within the students.

Another important difference is that in the $\mathrm{CM}$ the students can immediately check if they have solved the questions right. This allows students to express any doubt they could have and know why the answers are those at the moment. In the CL, by contrast, the exercise is not resolved until the next week, the topic can be forgotten by then and the students may be less curious about if their answers were correct and why.

In addition, the students in the CM have to do an essay to be submitted the following week. This helps them to study in depth on related topics and find, familiarize with and compare different available information sources.

Finally, students in the CL may feel less control over their scores (as these are averaged with the subgroup members ones) which may contribute to diminish their motivation.

On the other hand, the introduction of the blog achieved higher exam pass rate and average grade (Table 4). Moreover, the number of scores equal to or higher than 3.5 has also improved notably from 13 to $44 \%$.

Table 4. Results comparison of the examinations before and after the blog

\begin{tabular}{lcc} 
& Without blog & With blog \\
\hline Average grade (0-5) & 2.69 & 3.21 \\
Fail grades \% & 31.3 & 21.2 \\
N. of absentees (out of 70) & 3 & 4 \\
Grade $\geq 3.5 \%$ & 13 & 44 \\
\hline
\end{tabular}

With regard to the survey question: "Has the blog been positive during the study of the subject?" the students have generally answered "Frequently".

These good results may be due to:

- The capacity of the blog for fostering involvement within the students.

- The blog allows a lot of interaction.

- It has a big spatial extend (only need internet connection, you do not have to be at University).
- It is quick. As soon as you write something, it is published and available instantaneously.

- Wide distribution.

- Open resources.

- Easy to use.

- No need of any installations.

- No need of registration in anywhere.

- Continuous evaluation (grades at different moments, including evaluation of the skills in the final global grade and outer class essays.

\subsection{Academic courses 2008/09 and 2009/10}

When comparing the control group with the handled group (addition of some sessions based on $\mathrm{CM}, \mathrm{CL}$ and blog), better results were shown in the last one. These methodologies allow undergraduates not only to concentrate on writing down and copying the theoretical content, but also to work on the study and resolution of the exercise/s. These methods train aspects related to the initially mentioned skills: they provide undergraduates with an environment for meeting, working in groups, thinking or discussing, in an almost autonomous way.

\subsection{Difficulties and incentives}

To truly make a sensible evaluation of this study, it is necessary to consider the difficulties and the incentives found in the implementation of this experience. The difficulties are described in the following paragraphs.

One disadvantage is that designing the material, the lecture and checking the adaptation of the realized work to the proposed objectives continuously, involves a great deal of work for the professor and for the students. This is especially significant when developing the cases of the CM, i.e., the methodology that presented the best results. The case has to be, preferably, a multi-solution and realistic problem to increase the students' interest and their analyses, discussions and reflections. This is more difficult for some subjects (e.g., Geology) comparing to other subjects as Medicine or Laws (in which the CM is widely used).

A direct cause from the previous point is that the implementation of these methods implies a lot of time. Though, the amount of work and time follows a logarithmic curve because part of the work can be used the following years (always keeping it under review and update).

Another weakness is the number of students. It is easier to implement these teaching methods in optional subjects where there are not many students than in compulsory ones of the first year where they have big groups. That was the reason for using the seminars and the practical classes (where the students are divided in two groups). 
In addition, some students complain because these methodologies mean a large amount of work. Furthermore, some students do not contribute on solving the tasks: when doing teamwork, it cannot be assured that all the members of the team work equally.

Finally, it is difficult to finish always on time and 50 minutes may not be enough in some cases.

In spite of all the difficulties mentioned above, some incentives did exist.

It facilitates the adjustment to the Bologna process. As these methodologies imply a constant monitoring of the learning, needs and evaluation of the student, professors can easily make a multiple and continuous evaluation (base-points of the new plan).

Likewise, it is useful for training valuable skills for companies (teamwork, public speaking...).

The enhancement of the learning was proven. The retention of the information and the comprehension are bigger when discussion happens than when exhibition, reading or audio-visuals do.

More and more often, professors can find support from the institutions to introduce innovations to their lessons. In a lot of countries there is an institution which guarantees the spread of good teaching practices and keeps them under review.

And a final point is the personal job satisfaction. It is rewarding to observe the great students' progress in the end of the year.

\section{Conclusions}

The didactic role of professors is more considered now than it used to be, with an emphasis on students' learning outcomes. The establishment of ECEES evidences the importance of applying education methods that suit the new reforms, develop skills and ensure teaching quality. The research carried out introduces the application of CL, CM and a blog in some lectures where the students could be split into two groups. These methods were chosen because they facilitate universities to adapt to the rapidly changing educational policies.

The three methodologies help students to improve their comprehension of the subject through teamwork, listening to other classmates' ideas and discussing the information under a global collective reflexion. CM and CL are possible in a non-clinical and non-legislative setting, though some disadvantages (difficulty in designing the lectures, in finding cases libraries, in getting a small number of students and, the most important, the availability of time) exist. Professors have to decide on the frequency of the sessions and if the presented methods are worth trying.

The adoption of CM resulted more suitable than the $C L$ in the case of $1^{\text {st }}$ year-students where the learning outcomes resulted better than in CL. The reasons are that more guidance is given to students, that the answers are checked immediately during the pooling, that the extra essay internalizes more the acquired knowledge and that the students feel more control over their own marks. The introduction of the blog was also proved good results for consolidating the motivation.

Even so, CM and ICT have to complement the standard lectures, but not to substitute them. It was proven that designing the classes in a multifaceted manner by adding the CM could have an added value. The concept of education implies itself a multidimensional approach.

Modernizing teaching techniques is an issue that must still be addressed in our society (although these techniques have existed since decades). Nevertheless, a consolidation of these procedures is expected for the next years, especially in higher courses.

\section{References}

[1] B.O.E. núm, Real Decreto 1393/2007, de 29 de octubre, por el que se establece la ordenación de las enseñanzas universitarias oficiales. 2007.

[2] The official Bologna Process website 2010-2012 http://www.ehea.info/members.aspx. August 31 ${ }^{\text {st }}, 2012$.

[3] E. Alonso, Las agencias de evaluación en la acreditación docente universitaria. 2010.

[4] E. Ashby, The Academic Profession. Editor. Oxford University Press. London. 1969.

[5] Programa de Formación Docente de la UAM www.lauam.es/vicerrectorado/formacion_docente. August $31^{\mathrm{st}}, 2012$.

[6] R. Ellis, Quality Assurance for University Teaching. 1993.

[7] J.I. Pozo and M.P. Pérez, La psicología del aprendizaje universitario: de la adquisición de conocimientos a la formación de competencias. 2009.

[8] C. Monereo and J.I. Pozo, La universidad ante la nueva cultura educativa: enseñar y aprender para la autonomía. 2003.

[9] J.I. Pozo, et al., Nuevas formas de pensar la enseñanza y el aprendizaje. Editor. Grao. 2006.

[10] L.H. Anderman and V.S. Leake, "The ABCs of Motivation: An Alternative Framework for Teaching Preservice Teachers about Motivation".The Clearing House. 78 (5). 1994. pp. 192. 


\section{Appendices}

\section{Appendix A: Survey on professor evaluation}

Your opinion is important. Remember all the answers are totally anonymous.

NS/NC: you do not know.

\section{Gender:}

$\square$ Male

$\square$ Female

$\square \mathrm{NS} / \mathrm{NC}$

Age:

$\begin{array}{lll}\square 18 & \square 19 & \square 20 \\ \square 21 & \square 22 & \square 23-25\end{array}$

$\square 26-35$

$\square$ More the 26

\section{Scholarship obtained:}

$\square$ No $\quad \square$ Yes $\quad \square$ NS/NC

\section{Expected mark (from 0-10):}

$\square$ No attended $\quad \square$ Fail (0-4.9)

$\begin{array}{ll}\square \text { 5-6.9 } & \square 7-8.9 \\ \square \text { 8.9-9.9 } & \square 10\end{array}$

\section{$\square \mathrm{NS} / \mathrm{NC}$}

The professor explains with clarity:

$\square$ Totally disagree $\quad \square$ somewhat disagree

$\square$ Neither agree nor disagree

$\square$ somewhat agree $\quad \square$ agree

$\square$ Totally agree.

The professor is clear in her explanations:

The professor knows the subject very well:

The professor was available for consultations:

The professor had a receptive and friendly attitude:

The professor has attended the classes (justified absences or recovered missed classes):

The professor is usually on time:

On the whole, I am satisfied with the work delivered by the professor:

My interest decreased along the lecture:

Student involvement is fostered:

The importance of the subject is explained:

Students' efforts and achievements are related:

Several didactic resources are used in the lectures:

Critical discussion is encouraged:

Interest is shown and help is available to the students:

Evaluation is presented at the beginning of the course:

Co evaluation activities are promoted:

Finally, write any opinion or aspect that you may consider relevant. When you finish, click on the submit icon. 